\title{
Molecular farming of human cytokines and blood products from plants: Challenges in biosynthesis and detection of plant-produced recombinant proteins
}

\author{
Nicolau B. da Cunha, Giovanni R. Vianna, Thaina da Almeida Lima and Elíbio Rech \\ Synthetic Biology and Nanotechnology Group, Embrapa Genetic Resources and Biotechnology, Brasília, Brazil
}

\begin{abstract}
Plants have emerged as an attractive alternative to the traditional mammalian cell cultures or microbial cell-based systems system for the production of valuable recombinant proteins. Through recombinant DNA technology, plants can be engineered to produce large quantities of pharmaceuticals and industrial proteins of high quality at low costs. The recombinant production, by transgenic plants, of therapeutic proteins normally present in human plasma, such as cytokines, coagulation factors, anticoagulants, and immunoglobulins, represents a response to the ongoing challenges in meeting the demand for therapeutic proteins to treat serious inherited or acquired bleeding and immunological diseases. As the clinical utilization of fractionated plasma molecules is limited by high production costs, using recombinant biopharmaceuticals derived from plants represents a feasible alternative to provide efficient treatment. Plant-derived pharmaceuticals also reduce the potential risks to patients of infection with pathogens or unwanted immune responses due to immunogenic antigens. In this review, we summarize the recent advances in molecular farming of cytokines. We also examine the technological basis, upcoming challenges, and perspectives for the biosynthesis and detection of these molecules in different plant production platforms.
\end{abstract}

Received 10 JUN 2013

Revised 21 OCT 2013

Accepted 19 NOV 2013

Keywords: Cytokines · Glycoengineering · Molecular farming · Plant-based production - Recombinant plasma proteins

\section{Introduction}

Molecular farming is the production of recombinant pharmaceuticals, industrial proteins, and secondary metabolites, in plant systems. Since the biosynthesis of recombinant human growth hormone (hGH) by transgenic tobac-

Correspondence: Dr. Elíbio Rech, Synthetic Biology and Nanotechnology Group at Embrapa Genetic Resources and Biotechnology, Parque Estação Biológica, PqEB, Av. W5 Norte, 70770-917, Brasília, DF, Brazil

E-mail: elibio.rech@embrapa.br

Abbreviations: CaMV, cauliflower mosaic virus; $\mathrm{CHO}$, cultured Chinese hamster ovary cells; EPO, erythropoietin; GM-CSF, granulocyte-macrophage colony-stimulating factor; IFNs, human interferons; IGF-1, insulin-like growth factor 1; ILs, interleukins; M-CSF, macrophage colony-stimulating factor; PDs, plasma-derived proteins; PMPs, plant-made pharmaceuticals; rhEPO, recombinant human erythropoietin; TNF, tumor necrosis factor; TSP, total soluble protein.
Co in 1986, a wide range of recombinant plant-made pharmaceuticals (PMPs) have been expressed in an increasingly diverse number of crops and vegetable systems [1-3].

Transgenic plants are capable of folding and assembling complex structural glycoproteins - such as complete antibodies - and also of performing many of the post-translational modifications required for therapeutic function [2, 4]. Equally important is the fact that crops usually provide abundant biomass and have high biosynthetic capacity, requiring only simple elements such as light, minerals, and water to provide significant protein accumulation in their leaves, tubers, stems and seeds $[1,5]$. In addition, advances in transient expression mediated by virus-infected plants can be exploited to obtain high yields of raw protein in only a few days, and this system may constitute the new frontier for the rapid, staggered production of therapeutic proteins, primarily vaccines, under competitive conditions [6]. Transient expres- 
sion allows the cultivation of transgenic plants under controlled conditions to be staggered, permitting the production of pharmaceutical-grade therapeutic proteins on a large scale and at competitive costs [6-8].

Another important aspect of the production of therapeutic proteins in plants is the usually high safety standards of PMPs. In contrast to other available production platforms, notably the mammalian cell suspension, plants present a low risk of harboring mammalian pathogens, prions, human viruses, and oncogenes, providing a significant manufacturing advantage in terms of safety, quality, and product authenticity $[9,10]$.

Interest in the potential of plants as biofactories for therapeutic proteins is growing rapidly, with the development of different expression strategies, improved production facilities, and an increase in capital expenditure by biotechnology companies around the world [2]. Recently, the recombinant enzyme glucocerebosidase (GCD), developed by the Israeli company Protalix Biotherapeutics under the registered name of ELELYSO ${ }^{\mathrm{TM}}$, gained FDA approval for commercialization, becoming the first manufactured PMP to achieve marketable status [11]. ELELYSO ${ }^{\mathrm{TM}}$ is efficient in the treatment of type 1 Gaucher's disease, a lysosomal storage disorder that affects macrophages, and was synthesized at an industrial scale using a carrot cell suspension system that uses the C-terminal vacuolar sorting signal from tobacco chitinase [12]. Another drug candidate developed by Protalix is the chimeric monoclonal antibody pr-antiTNF (tumor necrosis factor). The molecule is a biosimilar version of Pfizer Enbrel $^{\mathrm{TM}}$, a potent drug synthesized by Chinese hamster ovary (CHO) cells and utilized to treat chronic inflammatory disorders, such as rheumatoid arthritis [13]. Pr-antiTNF was synthesized using the same technology as GCD, and presented the identical amino acid sequence and similar in vivo activity to Enbrel ${ }^{\mathrm{TM}}$ during preclinical trials (http://www.protalix.com/pipeline_products.html).

In 2010, after signing a Technology Investment Agreement grant of US\$ 21 million with the Defense Advanced Research Projects Agency (DARPA), the Canadian company Medicago started the development of an H1N1 virus-like particle influenza vaccine using agroinfiltrated tobacco plants [11]. The main purpose of the agreement was the development of a quick manufacturing alternative in case of a pandemic, made possible by the rapid, agile, transient expression of the vaccine in the leaves within $24 \mathrm{~h}$ after infiltration [14]. The vaccine is now undergoing Phase I clinical trials and could be efficiently synthesized on an industrial scale (about 10 million doses in one month), representing, along with the company's previously H5N1 vaccine (currently in Phase II clinical trials), one of the most promising PMPs in the pipeline [14]. Other PMPs have reached advanced stages of development and are now undergoing approval for Phase III clinical trials prior to commercialization. These include vaccine antigens, antibodies, therapeutic enzymes, growth factors, hormones, cytokines and other proteins present in the human bloodstream [2, 3, 11, 15-17].

Blood proteins are particularly interesting candidates for PMPs because they play key roles in metabolism and are associated with diseases that have significant social impact [18]. The different types of blood proteins can be divided into two major categories: (i) polypeptides associated with circulating cells; and (ii) plasma-derived proteins (PDs) that regulate important acellular processes, such as hormones, cytokines, enzymes, protease inhibitors, clotting factors, and bloodstream transporters of lipids, vitamins and ions [18]. Fractionated PDs are primarily utilized in the treatment of the different forms of acquired or congenital diseases, mainly the different forms of haemophilia and other bleeding and immunological disorders [18]. Also, this category of therapeutic proteins is invaluable for compensating for blood loss that results from trauma or surgery, in this way PDs contribute to saving and improving patients quality of life all over the globe [19].

Despite the positive impact resulting from the routine utilization of PDs in human health care, the use of blood substitutes in the 1980s is linked to a considerable increase in the spread of viruses and other infectious diseases in America [20, 21]. In the two decades that followed, concerns about the safety of blood products resulted in the improvement of manipulating facilities and a strengthening of regulatory control over concentrate production [22]. Nowadays laboratories accredited to produce PDs must follow specific measures in compliance with good manufacturing practices (GMP), including the rigorous selection of blood donors, sample testing, and product treatment during manipulation [23].

The adoption of GMP by manufacturers contributed to a consistent increase in the quality of products, but other issues still limit the large-scale production of PDs [20]. Despite the high demands of the market, manufactured PDs barely meet product demand and have high production costs, mostly due to the scarcity of well tested raw materials and the expensive multi-step fractioning/purification protocols required for drug manipulation [20]. Such limitations represent important challenges that have directed the scientific focus towards the development of alternative platforms for the recombinant production of PDs as virus-free products intended for replacement therapies [21, 24].

Whereas bacterial and yeast cells are commonly utilized to produce many important recombinant therapeutic proteins, they are unable to provide the intricate folding and complex post-translational modifications required for most PDs $[25,26]$. This gap was filled by cultured mammalian cells, which became the workhorse for recombinant plasma protein production. Mammalian cell suspensions are equipped with the specific enzymatic machinery capable of performing extensive post-translational modifications, mainly $\mathrm{N}$ - or $\mathrm{O}$-glycosylation, similarly to those of human proteins $[27,28]$. However, mam- 
malian cells present some drawbacks in terms of costeffectiveness, low cell density, and safety [25].

Thus, transgenic plants may constitute promising alternative systems for the large-scale production of high quality recombinant PDs at accessible costs [26, 29-31]. In this review, we examine the technological approaches available for the production of cytokines using plant systems. We also evaluate some of the recent attempts to improve product quality in vegetable platforms, looking at the recent advances in the field that will potentially drive the development of the next generation of cytokines.

\section{Cytokines produced by plant-based systems}

Cytokines are soluble hormone-like proteins, which are frequently glycosylated, secreted primarily by white blood cells [32]. These molecules are synthesized and secreted at the femto to picomolar range in response to autocrine or paracrine inducible stimuli, and act as chemical signals between the cellular and external environments [33]. Human cytokines are components of the immune system and also regulate a broad range of processes as diverse as cell proliferation, differentiation, and mobility [34-36]. Abnormal fluctuations in cytokine production or signalling are related to various pathological immune and inflammatory disorders, such as major depression, cancer, and Alzheimer's disease [37].

There are more than 100 well characterized cytokines, which can be conveniently grouped into eight distinct families distributed in two major functional classes [36]. Class I cytokines are the hematopoietins: (i) erythropoietin; (ii) cardiotrophin; (iii) macrophage colony-stimulating factor (M-CSF); (iv) granulocyte-macrophage colonystimulating factor (GM-CSF); and (v) interleukins (ILs) 2, 4, 12 and 13. The cytokines from Class II are: (i) the interferon (IFN) family (IFN- $\alpha$, IFN- $\beta$, IFN- $\gamma$, IFN- $\kappa$ and ILs 10 , 20 and 22); (ii) the platelet-derived growth factors (PDGF); (iii) TNFs; (iv) IL-1; (v) IL-7; (vi) the tumor growth factor (TGF-beta) families; and (vii) the chemokines [36].

The recombinant production of structurally simple cytokines traditionally relies on microbial systems [38]. For these simple cytokines the glycosylated products are active without the carbohydrate moiety or the hyperglycosylation provided by yeast does not interfere with the therapeutic function [25]. Cell suspensions of Escherichia coli and yeast are the most commonly utilized vehicles for the production of cytokines, and yields of more than $5 \mathrm{~g}$ of interferon per liter of cell culture are routinely obtained [39]. Although the expression levels associated with microbial systems are frequently high, the clinical usage of recombinant cytokines is still limited by high production costs [36]. Notwithstanding, different recombinant cytokines from microorganisms have been approved for clinical use in the treatment of neutropenia, leukemia, chronic hepatitis B and C [36].
In contrast, while the first PMPs date from almost 25 years ago, the development of plant-derived cytokines is an emerging field in molecular farming, with a few examples of advanced drug candidates in the pipeline [36]. The drawbacks that limit the commercial success of cytokines produced in plant systems are similar to those encountered by any other class of PMPs. Commonly, the addition of undesirable plant glycosylation is a major concern related to the unsatisfactory therapeutic performance of many plant-derived cytokines $[40,41]$. Although eukaryotes share many $N$-glycosylation steps along the secretory pathway, the final structures of $N$-complex glycans may differ considerably between plants and mammals [40]. In plants, the intermediate oligosaccharide

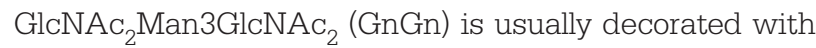
$\beta 1,2$-xylose and core $\alpha 1,3-$ fucose residues [41]. Mammals also present core fucosylation, but only $\alpha 1,6$-fucose residues are processed in mammalian system. Further elongation can occur in plants, with the attachment of $\beta 1,3$-galactose and $\alpha 1,4$-fucose residues to form Lewis-a epitopes $\left(\mathrm{Le}^{\mathrm{a}}\right)$ [41]. The removal of terminal $\mathrm{N}$ acetylglucosamine (GlcNAc) from GnGn carbohydrates, resulting in the formation of paucimannosidic $N$-glycans, is another usual processing that may occur in plants [42]. Also, plants lack the machinery for mucin-type O-glycosylation [42].

Major structural differences in glyco epitopes are frequently associated with protein instability, loss of biological function and immunogenicity. These represent important obstacles for manufacturing, and result in difficulties in standardization and validation of drug candidates [43]. However, several cytokines have already been synthesized in different plant systems, ranging from cell suspensions to transplastomic plants and virus-based production platforms for transient expression, as summarized in Table 1.

\subsection{Production of erythropoietin (EPO) in plants}

EPO is an extensively glycosylated cytokine of 30 to $38 \mathrm{kDa}$ that acts as a peptide hormone in the regulation of the differentiation of progenitor cells involved in the formation of mature erythrocytes [40]. The molecule is utilized in the treatment of anemia resulting from serious diseases, such as cancer, AIDS, and renal failure [44].

Recombinant human EPO (rhEPO) from CHO cells has become an important therapeutic product on the market, with a business volume of about 8 billion US\$ in 2003, and an estimated demand of $2 \mathrm{~kg}$ per year worldwide [45]. The rhEPOs display complex glycosylation with three $N$-linked (Asn-24, Asn-38 and Asn-83) and one O-linked (Ser-126) carbohydrate chains. The protein also requires sialylated $N$-glycans and processing of the carboxy-terminal arginine to be stable in the bloodstream and fully active [46, 47].

The production of rhEPO in plants began in 1993, with the development of protoplasts derived from transgenic 
Table 1. Examples of recombinant cytokines produced in different plant systems, showing the most utilized expression strategies and the final protein yields ${ }^{a}$

\begin{tabular}{|c|c|c|c|c|}
\hline Cytokine & Crop & Transformation Method & Expression Level/Yield & Reference \\
\hline \multicolumn{5}{|c|}{ Cell suspensions } \\
\hline erythropoietin & Tobacco & Agrobacterium-mediated & $0.0026 \%$ TSP & {$[44]$} \\
\hline G-CSF & Tobacco & Agrobacterium-mediated & $1.05 \times 10^{-4} \mathrm{~g} / \mathrm{L}$ & {$[93]$} \\
\hline GM-CSF & Tobacco & Agrobacterium-mediated & Max. $2.5 \times 10^{-4} \mathrm{~g} / \mathrm{L}$ & {$[54]$} \\
\hline GM-CSF & Tobacco & Agrobacterium-mediated & Max. $7.8 \times 10^{-4} \mathrm{~g} / \mathrm{L}$ & [55] \\
\hline IL-2 & Tobacco & Agrobacterium-mediated & $9 \times 10^{-5} \mathrm{~g} / \mathrm{L}$ & [64] \\
\hline IL-4 & Tobacco & Agrobacterium-mediated & $4.5 \times 10^{-4} \mathrm{~g} / \mathrm{L}$ & {$[64]$} \\
\hline IL-12 & Tobacco & Agrobacterium-mediated & $1.75 \times 10^{-4} \mathrm{~g} / \mathrm{L}$ & [70] \\
\hline GM-CSF & Rice & Biolistics & $0.129 \mathrm{~g} / \mathrm{L}$ & {$[57]$} \\
\hline GM-CSF & Rice & Biolistics & $0.28 \mathrm{~g} / \mathrm{L}$ & [56] \\
\hline GM-CSF & Rice & Biolistics & $0.29 \mathrm{~g} / \mathrm{L}$ & {$[94]$} \\
\hline GM-CSF & Rice & Biolistics & $0.25 \mathrm{~g} / \mathrm{L}$ & {$[58]$} \\
\hline IFN- $\gamma$ & Rice & Agrobacterium-mediated & $6.99 \times 10^{-4} \mathrm{mg} / \mathrm{g}$ cell & {$[81]$} \\
\hline IFN- $\alpha$ & Tomato & Lipofectin-mediated transformation & Max. $3.0 \times 10^{3} \mathrm{U} / \mathrm{g}$ & [79] \\
\hline \multicolumn{5}{|c|}{ Transgenic plants (nuclear transformation) } \\
\hline GM-CSF & Sugarcane & Biolistics & $0.02 \%$ TSP & [59] \\
\hline Murine GM-CSF & Tobacco & Agrobacterium-mediated & $0.019 \mathrm{mg} / \mathrm{g}$ & {$[95]$} \\
\hline IL-4 & Tobacco & Agrobacterium-mediated & $0.1 \% \mathrm{TSP}$ & [96] \\
\hline IL-4 & Tobacco & Agrobacterium-mediated & $0.086 \%$ TSP & {$[97]$} \\
\hline IL-10 & Tobacco & Agrobacterium-mediated & $0.27 \% \mathrm{TSP}$ & [97] \\
\hline IL-10 & Tobacco & Agrobacterium-mediated & Max. $0.043 \mathrm{mg} / \mathrm{g}$ & {$[98]$} \\
\hline IL-10 & Tobacco & Agrobacterium-mediated & Max. $0.037 \mathrm{mg} / \mathrm{g}$ & {$[68]$} \\
\hline IL-12 & Tobacco & Agrobacterium-mediated & $4 \times 10^{-5} \mathrm{mg} / \mathrm{g}$ & [69] \\
\hline IL-13 & Tobacco & Agrobacterium-mediated & $0.15 \% \mathrm{TSP}$ & [72] \\
\hline IL-18 & Tobacco & Agrobacterium-mediated & Max. $3.51 \times 10^{-4} \mathrm{mg} / \mathrm{g}$ & [73] \\
\hline cardiotrophin-1 & Tobacco & Biolistics & $0.14 \mathrm{mg} / \mathrm{g}$ & {$[99]$} \\
\hline $\begin{array}{l}\text { Fibroblast growth } \\
\text { factor } 8 \text { isoform b } \\
\text { (FGF8b) }\end{array}$ & Tobacco & Agrobacterium-mediated & $4.1 \%$ TSP & {$[100]$} \\
\hline IL-12 & Tomato & Agrobacterium-mediated & $7.3 \times 10^{-3} \mathrm{mg} / \mathrm{g}$ & [71] \\
\hline IFN- $\alpha 2$ & Aloe vera & Biolistics & Max. $9.53 \times 10^{2} \mathrm{IU} / \mathrm{g}$ & [101] \\
\hline IFN- $\alpha 2 b$ & Carrot & Agrobacterium-mediated & Max. $26.8 \times 10^{3} \mathrm{U} / \mathrm{g}$ & [82] \\
\hline GM-CSF & Tobacco & Agrobacterium-mediated & $1.3 \% \mathrm{TSP}$ & {$[61]$} \\
\hline GM-CSF & Tobacco & Agrobacterium-mediated & Max. $0.03 \%$ TSP & {$[60]$} \\
\hline Murine IL-2 & $\begin{array}{l}\text { Tobacco } \\
\text { Arabidopsis }\end{array}$ & Agrobacterium-mediated & $0.7 \% \mathrm{TSP}$ & [102] \\
\hline GM-CSF & Rice & Agrobacterium-mediated & Max. $0.014 \mu \mathrm{g} /$ seed & [103] \\
\hline IL-10 & Rice & Agrobacterium-mediated & $0.05 \mathrm{mg} / \mathrm{g}$ & [67] \\
\hline IGF-1 & Rice & Biolistics & up to $6.8 \%$ of total seed protein & {$[80]$} \\
\hline IL-2 & Potato & Agrobacterium-mediated & $1.15 \times 10^{5} \mathrm{U} / \mathrm{g}$ & {$[66]$} \\
\hline IL-4 & Potato & Agrobacterium-mediated & $0.08 \%$ TSP & [96] \\
\hline IFN- $\alpha 2 b$ & Potato & Agrobacterium-mediated & $560 \mathrm{IU} / \mathrm{g}$ & [78] \\
\hline IFN- $\alpha 8$ & & & & \\
\hline TNF- $\alpha$ & Potato & Agrobacterium-mediated & $0.015 \mathrm{mg} / \mathrm{g}$ & [104] \\
\hline Fish IFN- $\alpha 1$ & Potato & Agrobacterium-mediated & Max. $5400 \mathrm{U} / \mathrm{g}$ & [105] \\
\hline & Rice & Agrobacterium-mediated & Max. $820 \mathrm{U} / \mathrm{g}$ & \\
\hline \multicolumn{5}{|c|}{ Transplastomic plants } \\
\hline cardiotrophin-1 & Tobacco & Biolistics & Max $1.14 \mathrm{mg} / \mathrm{g}$ & [99] \\
\hline IFN- $\alpha 2 b$ & Tobacco & Biolistics & $20 \%$ TSP & {$[84]$} \\
\hline IGF-1 & Tobacco & Biolistics & Max. 32\% TSP & [85] \\
\hline
\end{tabular}


Table 1. Examples of recombinant cytokines produced in different plant systems, showing the most utilized expression strategies and the final protein yields ${ }^{a)}$ (continued)

\begin{tabular}{|c|c|c|c|c|}
\hline Cytokine & Crop & Transformation Method & Expression Level/Yield & Reference \\
\hline \multicolumn{5}{|c|}{ Transient expression - virus-based/Agroinfection } \\
\hline GM-CSF & N. benthamiana & Viral vector & Max. 2\% TSP & {$[106]$} \\
\hline Stem cell factor (SCF) & Tobacco & Viral vector & Max. $0.2 \mathrm{mg} / \mathrm{g}$ & [107] \\
\hline IL-3 & Tobacco & Viral vector & Max. $0.144 \mathrm{mg} / \mathrm{g}$ & [107] \\
\hline IGF-1 & Tobacco & Viral vector & Max. $0.25 \mathrm{mg} / \mathrm{g}$ & [107] \\
\hline Chicken IFN- $\alpha$ & Lettuce & Agroinfiltration/binary vector & $0.393 \mathrm{mg} / \mathrm{g}$ & [108] \\
\hline IFN- $\beta$ & Lettuce & Agroinfiltration/binary vector & $3.1 \times 10^{4} \mathrm{IU} / \mathrm{mL}$ & [109] \\
\hline
\end{tabular}

a) Adapted from Sirko et al. 2011 [36]. Max, maximum; IU, international unit. Note: All rhEPO information is in Table 2

tobacco BY2 cell lines, which were capable of accumulating very low levels of rhEPO (approximately $1 \times 10^{-9} \mathrm{mg} / \mathrm{g}$ of wet cells) [48]. Similar levels (up to $1.2 \times 10^{-3} \mathrm{mg} / \mathrm{L}$ ) were obtained from transgenic tobacco cell lines harboring the coding sequence of EPO and the endogenous $N$-terminal signal peptide for extracellular secretion under control of $35 \mathrm{~S}$ promoter of cauliflower mosaic virus (CaMV). Secretion was observed in protoplasts derived from transgenic cells but the protein presented only showed activity in vitro [44].

The constitutive expression of rhEPO was also observed in whole plants of tobacco and Arabidopsis sp. Although high transcription levels were detected in all transgenic lines, tobacco plants presented abnormal morphology with retarded vegetative growth and male sterility [49].

The initial setbacks in the development of functional rhEPO in plant systems corroborated the hypothesis that the differences in plant and mammalian glycosylation were crucial for the stability of the protein and for proper biological function [50]. To minimize such problems, different expression strategies have been developed in order to humanize plant glycosylation. One promising approach is to utilize the mutant moss Physcomitrella patens as a host for high quality production of rhEPO. An advantageous feature of $P$. patens is high frequency of homologous recombination for efficient gene targeting, enabling the specific knock out of the $\alpha 1,3$-fucosyltransferase and $\beta 1,2$-xylosyltransferase genes [51]. For example, high levels of stable and transiently produced rhEPO (max. $0.250 \mathrm{mg} / \mathrm{g}$ dry weight) were achieved in protoplasts of wild-type and $\Delta$-fuc-t $\Delta$-xyl-t mutant lines of $P$. patens by Weise and collaborators [47].

Another interesting strategy shown to be a promising tool for the generation of improved $\mathrm{hEPO}$ in plants is glycoengineering, the remodeling of complete mammalian biosynthetic pathways within host cells [45]. Transgenic tobacco lacking plant-specific glycosyltransferases and harboring mammalian $\beta 1,4$-mannosyl $-\beta, 4-N$-acetylglucosaminyltransferase (GnTIII), $\alpha 1,3$-mannosyl- $\beta 1,4-N$-acetylglucosaminyltransferase (GnTIV) and $\alpha 1,6$-mannosyl- $\beta 1,6-N$-acetylglucosaminyltransferase (GnTV) were utilized to modulate the plant glycosylation pathway toward the accumulation of rhEPO with complete human-type bisected and branched $N$-glycans [52].

Along with $\mathrm{N}$-glycosylation, terminal sialyation also seems to be crucial for the circulatory half-life and activity of rhEPO. Different glycoforms of biologically active biand multi-sialyated rhEPO were purified from mutant $\Delta$-fuc-t $\Delta$-xyl-t tobacco plants harboring the genes for branching, $\beta 1$,4-galactosylation, synthesis, transport, and transfer of sialic acid $[40,45]$. Examples of the improved recombinant production of EPO in glycoengineered plants are shown in Table 2.

\subsection{Production of human GM-CSF in plants}

GM-CSFs are small proteins $(22 \mathrm{kDa})$ secreted mainly by macrophages and $\mathrm{T}$ cells that act in the immune/inflammatory cascade [53]. GM-CSFs show little structural variation and are well tolerated by patients, thus constituting good candidates for PMPs [54].

Tobacco and rice cell suspensions are the most commonly utilized systems for GM-CSF production, and different protocols for manipulation of the culture growth medium are available for improving expression levels [55, 56]. The rice amylase Ramy3D promoter is the most efficient genetic element used to increase the final GM-CSF expression in cell suspensions of rice, yielding up to $0.129 \mathrm{~g} / \mathrm{L}$ of culture [57]. The silencing of rice $\alpha$-amylase and cysteine proteinase combined with the co-expression of the cytokine and a protease inhibitor increases protein secretion and expression levels at least two-fold [58].

Constitutive GM-CSF production in whole plants was also achieved, but at low levels. Transgenic sugarcane and tobacco plants were able to accumulate 0.02 and $0.22 \%$ TSP (total soluble protein) respectively in the leaves, whereas transgenic tobacco seeds produced up to $1.3 \% \operatorname{TSP}[59,60]$. In fact, seed endosperm, rather than leaves, seems to be a more promising vehicle for the stable synthesis of GM-CSF. For instance, biologically active 


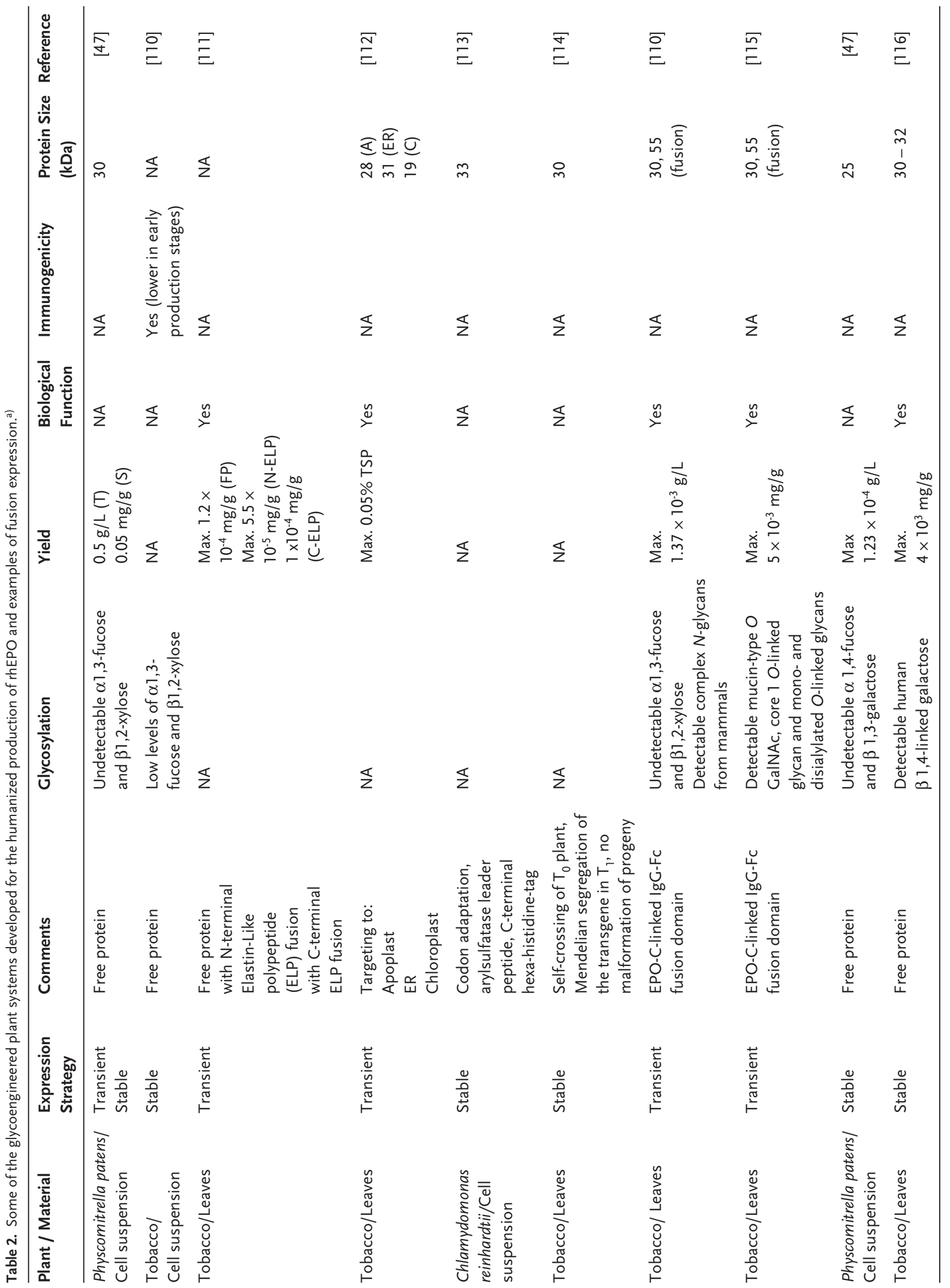


fractions of this cytokine were obtained in rice seeds using the glutelin promoter Gt1 at 1.3\% TSP [61].

\subsection{Production of ILs in plants}

The normal function of the immune system depends largely on the synthesis of ILs, signaling proteins that are synthesized primarily by white blood cells [62]. Deficiency in IL production is associated with rare autoimmune diseases and immune failure. [63].

The first ILs expressed in plant systems were IL-2 and IL-4, which accumulated at low levels in tobacco cell suspensions [64]. In this example, most of the ILs were retained inside cells and only the secreted fractions presented biological function [64]. As alternatives to secretion, protein targeting and the synthesis of ILs as protein fusions seem to be promising strategies for improving recombinant IL production. The IL-2 targeted to the ER of potato tubers and the IL-4 fused to elastin in tobacco leaves presented high stability after translation, but were accumulated at low levels, $115 \mathrm{U}$ and $0.08 \%$ TSP, respectively $[65,66]$.

Advances have also been made in the expression of plant-derived IL-10 and IL-12. Functional IL-10 has been produced in rice seeds (showing higher activity than the commercially available product from $E$. coli), and tobacco leaves (up to $0.037 \mathrm{mg} / \mathrm{g}$ of fresh weight) $[67,68]$. Furthermore, high expression levels of fully active recombinant IL-12 were observed in tobacco leaves infiltrated with two Agrobacterium spp. strains (5\% TSP) and in crude extracts of tomato $\left(7.3 \times 10^{-3} \mathrm{mg} / \mathrm{g}\right)$ [69-71]. The tomato IL-12 also presented a biological function comparable with its commercial E. coli counterpart [71]. Other ILs such as IL-13 and IL-18, have also been stably produced in tobacco plants, but at low levels [72, 73].

\subsection{Boosting expression in chloroplasts of human interferons (IFNs) and insulin-like growth factor 1 (IGF-1)}

Since the end of the 1990s, IFNs have been evaluated as potential candidates for molecular farming. IFNs present diverse molecular masses and are potent triggers of protective defenses of the immune system against pathogens and different types of tumors [74]. Recombinant IFNs from microbes are commonly used to treat Kaposi's sarcoma, myeloid leukaemia, and chronic hepatitis A and C, but microbial produced IFNs are expensive [75].

Attempts to obtain a cost-effective IFN from plants have led to the development of Locteron ${ }^{\circledR}$, a recombinant IFN- $\alpha 2 \mathrm{~b}$ synthesized by the defunct company Biolex [11, 76]. The drug candidate is produced using the LEX system $^{\mathrm{SM}}$, a high-throughput platform that uses the aquatic plant Lemna minor, commonly known as duckweed, for the large-scale production of glycan engineered monoclonal antibodies and interferons [15]. Locteron ${ }^{\circledR}$ has since 
been licensed by Dutch company OctoPlus NV and has completed Phase IIb clinical trials, becoming one of the most advanced recombinant therapeutic cytokines in the pipeline (http://www.octoplus.nl/files/4713/4676/5370/ OctoPlus_announces_publication_of_positive_Locteron_ interim_Phase_IIb_data.pdf).

IGF-1 is a $7.6 \mathrm{kDa}$ cytokine-like hormone structurally similar to insulin that mediates the anabolic action of the human growth hormone (hGH) and is utilized worldwide in the treatment of growth disorders during childhood [77]. Both, IFN- $\alpha 2 b$ and IGF-1, have been expressed in transgenic crops including: (i) potato tubers (560 IU of IFN- $\alpha 2 \mathrm{~b} / \mathrm{g}$ ); (ii) tomato and tobacco leaves (923 IU of IFN- $\alpha / \mathrm{g}$ and $3 \mathrm{mg}$ of IFN- $\alpha 2 \mathrm{~b} / \mathrm{g}$ respectively); (iii) rice seeds (IGF-1, 6.8\% TSP); and (iv) rice cell suspensions (up to $6.9 \times 10^{-4} \mathrm{ng}$ of IFN $\gamma / \mathrm{g}$ ) [78-81]. Also, considerably high yields of functional IFN- $\alpha 2 b$ have been achieved by apoplast targeting in young carrot leaves $\left(26.8 \times 10^{3} \mathrm{IU} / \mathrm{g}\right)$ and roots $\left(8.56 \times 10^{3} \mathrm{IU} / \mathrm{g}\right)$ [82].

The stable transformation of the tobacco plastid genome has turned into a promising approach to increase the final yields of recombinant cytokines, especially IFNs and IGF-1 [83]. Homoplasmic transplastomic tobacco plants, developed by researchers at the University of Central Florida (US), could accumulate IFN- $\alpha 2 \mathrm{~b}$ at levels up to 20\% TSP (3 mg/g of leaf FW) [84]. The molecules presented in vitro biological activity similar to the interferon marketed as PEG-Intron ${ }^{\mathrm{TM}}$, a drug utilized to protect cells from cytopathic viral replication and inhibit early human immunodeficiency virus (HIV) infection [84]. Also, IFN- $\alpha 2 \mathrm{~b}$ presented in vivo antitumor protection. The transgenic plants expressing IFN- $\alpha 2 b$ received United States Department of Agriculture Animal and Plant Health Inspection Service (USDA-APHIS) approval for field growth, becoming the first example of field production of a plant-derived plasma protein, taking a crucial step towards clinical trials and commercialization [84].

IGF-1 was also successfully accumulated in the chloroplasts of tobacco using the endogenous chloroplast $p s b A$ promoter. Final yields in routine cultivation were $11.3 \%$ TSP, but reached $32 \%$ TSP when plants were submitted to continuous photoperiod [85].

Despite the myriad of reports of accumulation of PMPs in chloroplasts, there are no companies seeking to explore the chloroplast expression technology for cytokine production, as chloroplasts are unable to provide the complex post-translational modifications required for most cytokines to function properly in vivo $[2,86]$

\section{Conclusions and perspectives}

Among the novel classes of therapeutic molecules under development, recombinant proteins are the fastest growing candidates to fulfill customer demands [41]. The diversification of current plant-based expression systems and the improvement of existing technology platforms have allowed the development of new, efficient drug candidates. Some plant-produced drug candidates have reached advanced stages of preclinical trials and achieved basic commercial requirements such as high production speed, scalability, safety, high-quality manufacturing, and reduced costs [28].

The introduction of the first PMP into the pharmaceutical market paves the way for the further development of recombinant cytokines. Recent progress in understanding the nature of many immune system disorders has contributed to a substantial increase in the demand for cytokines worldwide [11]. However, technical and regulatory challenges, mainly undesirable glycosylation, still limit the development of affordable products and make cytokine investment less attractive to investors, with some pioneering companies facing economic challenges or bankruptcy $[2,36]$.

Protein targeting is an interesting strategy to avoid plant glycosylation but is insufficient when the cytokine of interest needs the correct galactosylation and sialylation for half-life and in vivo efficacy [43]. The utilization of $\Delta$-fuc-t $\Delta$-xyl-t mutant lines and those harboring GnTIII, GnTIV and GnTV has already proven to be suitable for the biosynthesis of functional cytokines, but such hosts strains are only available in a few plant systems, most notably tobacco and P. patens, therefore this technology is currently not applicable to other crops, such as cereals and legumes [41, 47, 51].

In this context, zinc finger nucleases (ZFNs) and transcription activator-like effectors nucleases (TALENs) are promising molecular tools for the humanization of the $N$-glycosylation of cytokines in plants [87]. These DNAmodifying proteins enable the targeted alteration of genes in a wide range of cell types and organisms, with the potential to generate a substantial impact on the commercial production of PMPs [88]. Engineered ZFNs and TALENs can be designed to target any genomic location of interest, allowing genome editing with high accuracy and precision, even within complex genomes [89, 90].

Genome editing promises to facilitate genetic manipulation of $\mathrm{N}$-glycan associated genes to a much broader extent than the currently available molecular tools, potentially enhancing expression levels and permitting structural manipulation of complex cytokines without altering biological function.

Some plant systems still provide low yields of recombinant cytokines, limiting the commercial utilization of such systems due to production insufficient in speed and quantities to meet customer demands [36]. It is crucial to develop efficient strategies to boost recombinant expression of cytokines in order to achieve affordable manufacturing standards.

Recently, a new promising class of genetic tools related to the modulation of gene transcription was discovered in mammalian pluripotent cells: the super enhancers [91]. 
These are unusual domains formed by clusters of enhancers up to $50 \mathrm{~kb}$ in size, which are densely occupied by master regulators involved in the activation of transcription in embryonic stem cells (ESCs) [92]. Super enhancers play key roles in gene expression and cell identity and can be explored, in the future, as a means to boost transcription of cytokine genes in different plant expression systems.

Genome-editing technology and strategies to boost recombinant expression in plants may constitute two powerful approaches for the large-scale production of recombinant cytokines with improved product quality and humanized post-translational modifications. We believe that both of these strategies represent the most exciting and promising subjects for future research in the field of molecular farming.

This study was supported in part by the Brazilian National Council for Scientific and Technological Development (CNPq), the Brazilian Foundation Coordination for the Improvement of Higher Education Personnel (CAPES), Fundação de Apoio a Pesquisa (FAP-DF), and Embrapa Genetic Resources and Biotechnology.

The authors declare no conflict of interest.

\section{References}

[1] Xu, J., Dolan, M. C., Medrano, G., Cramer, C. L., Weathers, P. J., Green factory: Plants as bioproduction platforms for recombinant proteins. Biotechnol. Adv. 2012, 30, 1171-1184.

[2] Paul, M., Ma, J. K. C., Plant-made pharmaceuticals: Leading products and production platforms. Biotechnol. Appl. Biochem. 2011, 58, 58-67.

[3] Paul, M., Dolleweerd, C. V., Drake, P. M. W., Reljic, R. et al., Molecular pharming: Future targets and aspirations. Hum. Vaccin. 2011, 7, 375-382.

[4] Tiwari, S., Verma, P. C., Singh, P. K., Tuli, R., Plants as bioreactors for the production of vaccine antigens. Biotechnol. Adv. 2009, 27, 449-467.

[5] Vianna, G. R., Cunha, N. B., Murad, A. M., Rech, E. L., Soybeans as bioreactors for biopharmaceuticals and industrial proteins. Genet. Mol. Res. 2011, 10, 1733-1752.

[6] Tremblay, R., Wang, D., Jevnikar, A. M., Ma, S., Tobacco, a highly efficient green bioreactor for production of therapeutic proteins. Biotechnol. Adv. 2010, 28, 214-221.

[7] Gleba, Y., Klimyuk, V., Marillonnet, S., Magnifection - A new platform for expressing recombinant vaccines in plants. Vaccine. 2005, 23, 2042-2048

[8] Rech, E. L., Seeds, recombinant DNA and biodiversity. Seed Sci. Res. 2012, 22, S36-S44.

[9] Ma, J. K. C., Drake, P. M. W., Christou, P., The production of recombinant pharmaceutical proteins in plants. Nat. Rev. Genet. 2003, 4, 794-805.

[10] Davies, H. M., Commercialization of whole-plant systems for biomanufacturing of protein products: evolution and prospects. Plant Biotechnol. J. 2010, 8, 845-861.

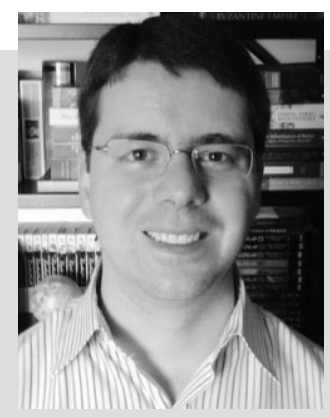

Dr. Nicolau Brito da Cunha is a postdoctoral research associate at the Laboratory of Synthetic Biology at Embrapa Genetic Resources and Biotechnology. He participates in different research projects focusing on the metabolic engineering of soybean plants for the production of biofuels and also the biosynthesis of recombinant therapeutic proteins in soybeans. He earned his PhD in Molecular Biology from University of Brasilia in 2012.

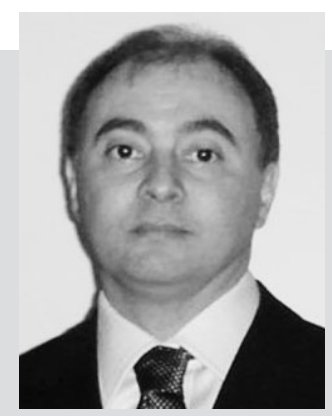

Dr. Giovanni R. Vianna is a Researcher from Embrapa Genetics Resources and Biotechnology since 2002, when he earned his PhD in Molecular Biology from the University of Brasília. His current research utilizes soybean plants to express molecules of industrial and pharmaceutical interest. He also participates in several studies in plant molecular biology, mainly the targeted expression of foreign genes in crops for better responses to biotic and abiotic stresses and, also, in the improvement of the production of biofuels by the engineering of metabolic pathways related to the biosynthesis of fatty acids in soybeans.

[11] Paul, M. J., Teh, A. Y., Twyman, R. M., Ma, J. K., Target product selection - -where can Molecular Pharming make the difference? Curr. Pharm. Des. 2013, 19, 5478-85

[12] Shaaltiel, Y., Bartfeld, D., Hashmueli, S., Baum, G. et al., Production of glucocerebrosidase with terminal mannose glycans for enzyme replacement therapy of Gaucher's disease using a plant cell system. Plant Biotechnol. J. 2007, 5, 579-590.

[13] Thalayasingam, N., Isaacs, J. D., Anti-TNF therapy. Best Pract. Res. Clin. Rheumatol. 2011, 25, 549-567.

[14] Landry, N., Ward, B. J., Trépanier, S., Montomoli, E. et al., Preclinical and clinical development of plant-made virus-like particle vaccine against avian H5N1 influenza. PLoS One. 2010, 5.

[15] De Leede, L. G., Humphries, J. E., Bechet, A. C., Van Hoogdalem, E. J. et al., Novel controlled release Lemna-derived IFN-alpha2b (Locteron): pharmacokinetics, pharmacodynamics, and tolerability in a phase I clinical trial. J. Interferon Cytokine Res. 2008, 28, 113122.

[16] Sparrow, P. A., Irwin, J. A., Dale, P. J., Twyman, R. M., Ma, J. K., Pharma-Planta: road testing the developing regulatory guidelines for plant-made pharmaceuticals. Transgenic Res. 2007, 16, 147-161.

[17] Obembe, O. O., Popoola, J. O., Leelavathi, S., Reddy, S. V., Advances in plant molecular farming. Biotechnol. Adv. 2011, 29, 210-222.

[18] Burnouf, T., Recombinant plasma proteins. Vox Sang. 2011, 100, 68 83.

[19] Pipe, S. W., Hemophilia: New Protein Therapeutics. Hematology Am. Soc. Hematol. Educ. Program. 2010, 2010, 203-209.

[20] Pipe, S. W., The promise and challenges of bioengineered recombinant clotting factors. J. Thromb. Haemost. 2005, 3, 1692-1701. 
[21] Pipe, S. W., Recombinant clotting factors. Thromb. Haemost. 2008, $99,840-850$

[22] Farrugia, A., Robert, P., Plasma protein therapies: current and future perspectives. Best Pract. Res. Clin. Haematol. 2006, 19, 243-258.

[23] Burnouf, T., Modern Plasma Fractionation. Transfus. Med. Rev. 2007, 21, 101-17.

[24] Kurachi, K., Davie, E. W., Isolation and characterization of a cDNA coding for human factor IX. Proc. Natl. Acad. Sci. U S A. 1982, 79, 6461-6464

[25] Demain, A. L., Vaishnav, P., Production of recombinant proteins by microbes and higher organisms. Biotechnol. Adv. 2009, 27, 297-306.

[26] Egelkrout, E., Rajan, V., Howard, J. A., Overproduction of recombinant proteins in plants. Plant Sci. 2012, 184, 83-101.

[27] Grillberger, L., Kreil, T. R., Nass, S., Reiter, M., Emerging trends in plasma-free manufacturing of recombinant protein therapeutics expressed in mammalian cells. Biotechnol. J. 2009, 4, 186-201.

[28] Melnik, S., Stoger, E., Green Factories for Biopharmaceuticals. Curr. Med. Chem. 2013, 20, 1038-1046.

[29] Xu, J., Ge, X., Dolan, M. C., Towards high-yield production of pharmaceutical proteins with plant cell suspension cultures. Biotechnol. Adv. 2011, 29, 278-299.

[30] Streatfield, S. J., Approaches to achieve high-level heterologous protein production in plants. Plant Biotechnol. J. 2007, 5, 2-15.

[31] Stoger, E., Sack, M., Perrin, Y., Vaquero, C., et al. Practical considerations for pharmaceutical antibody production in different crop systems. Mol. Breed. 2002, 9, 149-58.

[32] Tayal, V., Kalra, B. S., Cytokines and anti-cytokines as therapeutics - an update. Eur. J. Pharmacol. 2008, 579, 1-12.

[33] Cutler, A., Brombacher, F., Cytokine Therapy. Ann. N. Y, Acad. Sci. 2005, 1056, 16-29.

[34] Snykers, S., Vanhaecke, T., Papeleu, P., Luttun, A. et al., Sequential Exposure to Cytokines Reflecting Embryogenesis: The Key for in vitro Differentiation of Adult Bone Marrow Stem Cells into Functional Hepatocyte-like Cells. Toxicol. Sci. 2006, 94, 330-341.

[35] Kinoshita, T., Miyajima, A., Cytokine regulation of liver development. Biochim. Biophys. Acta. 2002, 1592, 303-312.

[36] Sirko, A., Vanek, T., Góra-Sochacka, A., Redkiewicz, P., Recombinant Cytokines from Plants. Int. J. Mol. Sci. 2011, 12, 3536-3552.

[37] Dinarello, C. A., Biologic basis for interleukin-1 in disease. Blood. 1996, 87, 2095-2147.

[38] Imaizumi, K., Nishikawa, S.-I., Tarui, H., Akuta, T., High-level expression and efficient one-step chromatographic purification of a soluble human leukemia inhibitory factor (LIF) in Escherichia coli. Protein Expr. Purif. 2013, 90, 20-26.

[39] Xie, Y. F., Chen, H., Huang, B. R., Expression, purification and characterization of human IFN-1 in Pichia pastoris. J. Biotechnol. 2007, 129, 472-480.

[40] Castilho, A., Neumann, L., Gattinger, P., Strasser, R. et al., Generation of Biologically Active Multi-Sialylated Recombinant Human EPOFc in Plants. PLoS One. 2013, 8.

[41] Castilho, A., Steinkellner, H., Glyco-engineering in plants to produce human-like N-glycan structures. Biotechnol. J. 2012, 7, 1088-1098.

[42] Gomord, V., Fitchette, A.-C., Menu-Bouaouiche, L., Saint-JoreDupas, C. et al., Plant-specific glycosylation patterns in the context of therapeutic protein production. Plant Biotechnol. J. 2010, 8, 564587.

[43] Gomord, V., Chamberlain, P., Jefferis, R., Faye, L., Biopharmaceutical production in plants: problems, solutions and opportunities. Trends Biotechnol. 2005, 23, 559-565.

[44] Matsumoto, S., Ikura, K., Ueda, M., Sasaki, R., Characterization of a human glycoprotein (erythropoietin) produced in cultured tobacco cells. Plant Mol. Biol. 1995, 27, 1163-1172.

[45] Jez, J., Castilho, A., Grass, J., Vorauer-Uhl, K. et al., Expression of functionally active sialylated human erythropoietin in plants. Biotechnol. J. 2013, 8, 371-382.
[46] Tsuda, E., Goto, M., Murakami, A., Akai, K. et al., Comparative structural study of $\mathrm{N}$-linked oligosaccharides of urinary and recombinant erythropoietins. Biochemistry. 1988, 27, 5646-5654.

[47] Weise, A., Altmann, F., Rodriguez-Franco, M., Sjoberg, E. R. et al., High-level expression of secreted complex glycosylated recombinant human erythropoietin in the Physcomitrella $\Delta$-fuc-t $\Delta$ - xyl —-t mutant. Plant Biotechnol. J. 2007, 5, 389-401.

[48] Matsumoto, S., Ishii, A., Ikura, K., Ueda, M., Sasaki, R., Expression of Human Erythropoietin in Cultured Tobacco Cells. Biosci. Biotechnol. Biochem. 1993, 57, 1249-1252.

[49] Cheon, B., Kim, H., Oh, K., Bahn, S. et al., Overexpression of human erythropoietin (EPO) affects plant morphologies: retarded vegetative growth in tobacco and male sterility in tobacco and Arabidopsis. Transgenic Res. 2004, 13, 541-549.

[50] Paulus, K. E., Mahler, V., Pabst, M., Kogel, K.-H. et al., Silencing

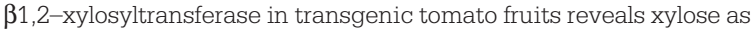
constitutive component of IgE binding epitopes. Front. Plant Sci. 2011, 2, 1-12.

[51] Koprivova, A., Stemmer, C., Altmann, F., Hoffmann, A. et al., Targeted knockouts of Physcomitrella lacking plant-specific immunogenic N-glycans. Plant Biotechnol J. 2004, 2, 517-523.

[52] Castilho, A., Gattinger, P., Grass, J., Jez, J. et al., N-Glycosylation engineering of plants for the biosynthesis of glycoproteins with bisected and branched complex N-glycans. Glycobiology. 2011, 21, 813-823.

[53] Pessach, I., Shimoni, A., Nagler, A., Granulocyte-colony stimulating factor for hematopoietic stem cell donation from healthy female donors during pregnancy and lactation: what do we know? Hum. Reprod. Update. 2013, 19, 259-267.

[54] James, E. A., Wang, C., Wang, Z., Reeves, R., et al., Production and Characterization of Biologically Active Human GM-CSF Secreted by Genetically Modified Plant Cells. Protein Expr. Purif. 2000, 19, 131-138.

[55] Lee, J.-H., Kim, N.-S., Kwon, T.-H., Jang, Y.-S., Yang, M.-S., Increased production of human granulocyte-macrophage colony stimulating factor (hGM-CSF) by the addition of stabilizing polymer in plant suspension cultures. J. Biotechnol. 2002, 96, 205-211.

[56] Kim, N. -S., Kim, T. -G., Jang, Y. -S., Shin, Y. .J. et al., Amylase gene silencing by RNA interference improves recombinant hGM-CSF production in rice suspension culture. Plant Mol. Biol. 2008, 68, 369-377.

[57] Shin, Y. -J., Hong, S. -Y., Kwon, T. -H., Jang, Y. -S., Yang, M. -S., High level of expression of recombinant human granulocyte-macrophage colony stimulating factor in transgenic rice cell suspension culture. Biotechnol. Bioeng. 2003, 82, 778-783.

[58] Kim, T. -G., Lee, H. -J., Jang, Y. -S., Shin, Y. -J. et al., Co-expression of proteinase inhibitor enhances recombinant human granulocyte-macrophage colony stimulating factor production in transgenic rice cell suspension culture. Protein Expr. Purif. 2008, 61, 117-121.

[59] Wang, M. -L., Goldstein, C., Su, W., Moore, P., Albert, H., Production of biologically active GM-CSF in sugarcane: a secure biofactory. Transgenic. Res. 2005, 14, 167-178.

[60] Sardana, R., Alli, Z., Dudani, A., Tackaberry, E. et al., Biological Activity of Human Granulocyte-Macrophage Colony Stimulating Factor is Maintained in a Fusion with Seed Glutelin Peptide. Transgenic Res. 2002, 11, 521-531.

[61] Sardana, R., Dudani, A., Tackaberry, E., Alli, Z. et al., Biologically active human GM-CSF produced in the seeds of transgenic rice plants. Transgenic Res. 2007, 16, 713-721.

[62] Wang, X., Lee, D. A., Wang, Y., Wang, L. et al., Membrane-bound interleukin-21 and CD137 ligand induce functional human natural killer cells from peripheral blood mononuclear cells through STAT-3 activation. Clin. Exp. Immunol. 2013, 172, 104-12. 
[63] Williams, P., Galipeau, J., GMCSF-Interleukin fusion cytokines induce novel immune effectors that can serve as biopharmaceuticals for treatment of autoimmunity and cancer. J. Intern. Med. 2011, 269, 74-84.

[64] Magnuson, N. S., Linzmaier, P. M., Reeves, R., An, G. et al., Secretion of Biologically Active Human Interleukin - 2 and Interleukin - 4 from Genetically Modified Tobacco Cells in Suspension Culture. Protein Expr. Purif. 1998, 13, 45-52.

[65] Patel, J., Zhu, H., Menassa, R., Gyenis, L. et al., Elastin-like polypeptide fusions enhance the accumulation of recombinant proteins in tobacco leaves. Transgenic Res. 2007, 16, 239-249.

[66] Park, Y., Cheong, H., Expression and Production of Recombinant Human Interleukin-2 in Potato Plants. Protein Expr Purif. 2002, 25, 160-165.

[67] Fujiwara, Y., Aiki, Y., Yang, L., Takaiwa, F. et al., Extraction and purification of human interleukin-10 from transgenic rice seeds. Protein Expr. Purif. 2010, 72, 125-130.

[68] Bortesi, L., Rossato, M., Schuster, F., Raven, N. et al., Viral and murine interleukin-10 are correctly processed and retain their biological activity when produced in tobacco. BMC Biotechnol. 2009, 9, $1-13$

[69] Gutiérrez-Ortega, A., Ávila-Moreno, F., Saucedo-Arias, L. J., Sánchez-Torres, C., Gómez-Lim, M. Á., Expression of a single-chain human interleukin-12 gene in transgenic tobacco plants and functional studies. Biotechnol. Bioeng. 2004, 85, 734-740.

[70] Kwon, T. H., Seo, J. E., Kim, J., Lee, J. H. et al., Expression and secretion of the heterodimeric protein interleukin-12 in plant cell suspension culture. Biotechnol. Bioeng. 2003, 81, 870-875.

[71] Gutiérrez-Ortega, A., Sandoval-Montes, C., Olivera-Flores, T. J., Santos-Argumedo, L., Gómez-Lim, M. Â., Expression of Functional Interleukin-12 from Mouse in Transgenic Tomato Plants. Transgenic Res. 2005, 14, 877-885.

[72] Wang, D. J., Brandsma, M., Yin, Z., Wang, A. et al., A novel platform for biologically active recombinant human interleukin-13 production. Plant Biotechnol. J. 2008, 6, 504-515.

[73] Zhang, B., Yang, Y.-H., Lin, Y.-M., Rao, Q. et al., Expression and production of bioactive human interleukin-18 in transgenic tobacco plants. Biotechnol. Lett. 2003, 25, 1629-1635.

[74] Moriguchi, H., Sato, C., Treatment of SARS with human interferons. Lancet. 2003, 362, 1159.

[75] Heim, M. H., Intracellular signalling and antiviral effects of interferons. Dig. Liver Dis. 2000, 32, 257-263.

[76] Twyman, R. M., Schillberg, S., R., F., Transgenic plants in the biopharmaceutical market. Expert Opin. Emerg. Drugs. 2005, 10, 185218.

[77] Forbes, B. E., Molecular mechanisms underlying insulin-like growth factor action: How mutations in the GH: IGF axis lead to short stature. Pediatr. Endocrinol. Rev. 2011, 8, 374-381.

[78] Ohya, K., Matsumura, T., Ohashi, K., Onuma, M., Sugimoto, C., Expression of two subtypes of human IFN-alpha in transgenic potato plants. J. Interferon Cytokine Res. 2001, 21, 595-602.

[79] Sawahel, W. A., The production of transgenic potato plants expressing human alpha-interferon using lipofectin-mediated transformation. Cell. Mol. Biol. Lett. 2002, 7, 19-29.

[80] Xie, T., Qiu, Q., Zhang, W., Ning, T. et al., A biologically active rhIGF1 fusion accumulated in transgenic rice seeds can reduce blood glucose in diabetic mice via oral delivery. Peptides. 2008, 29, 18621870.

[81] Chen, T.-L., Lin, Y.-L., Lee, Y.-L., Yang, N.-S., Chan, M.-T., Expression of bioactive human interferon-gamma in transgenic rice cell suspension cultures. Transgenic Res. 2004, 13, 499-510.

[82] Luchakivskaya, Y., Kishchenko, O., Gerasymenko, I., Olevinskaya, Z. et al., High-level expression of human interferon alpha-2b in transgenic carrot (Daucus carota L.) plants. Plant Cell Rep. 2011, 30, 407-415.
[83] Sharma, A. K., Sharma, M. K., Plants as bioreactors: Recent developments and emerging opportunities. Biotechnol. Adv. 2009, 27, 811-832.

[84] Arlen, P. A., Falconer, R., Cherukumilli, S., Cole, A. et al., Field production and functional evaluation of chloroplast-derived interferon- $\alpha 2 b$. Plant Biotechnol. J. 2007, 5, 511-525.

[85] Daniell, H., Ruiz, G., Denes, B., Sandberg, L., Langridge, W., Optimization of codon composition and regulatory elements for expression of human insulin like growth factor-1 in transgenic chloroplasts and evaluation of structural identity and function. BMC Biotechnol. 2009, 9, 1-16.

[86] Scotti, N., Rigano, M. M., Cardi, T., Production of foreign proteins using plastid transformation. Biotechnol. Adv. 2012, 30, 387-397.

[87] Mahfouz, M. M., Li, L., TALE nucleases and next generation GM crops. GM Crops. 2011, 2, 99-103.

[88] Joung, J. K., Sander, J. D., TALENs: a widely applicable technology for targeted genome editing. Nat. Rev. Mol. Cell Biol. 2013, 14, 49-55.

[89] Sanjana, N. E., Cong, L., Zhou, Y., Cunniff, M. M. et al., A transcription activator-like effector toolbox for genome engineering. Nat. Protoc. 2012, 7, 171-192.

[90] Ramalingam, S., Kandavelou, K., Rajenderan, R., Chandrasegaran, S., Creating Designed Zinc-Finger Nucleases with Minimal Cytotoxicity. J. Mol. Biol. 2011, 405, 630-641.

[91] Lovén, J., Hoke, Heather A., Lin, Charles Y., Lau, A. et al., Selective Inhibition of Tumor Oncogenes by Disruption of Super-Enhancers. Cell. 2013, 153, 320-334.

[92] Whyte, W. A., Orlando, D. A., Hnisz, D., Abraham, B. J. et al., Master Transcription Factors and Mediator Establish Super-Enhancers at Key Cell Identity Genes. Cell. 2013, 153, 307-319.

[93] Kwon, T.-H., Kim, Y.-S., Lee, J.-H., Yang, M.-S., Production and secretion of biologically active human granulocyte-macrophage colony stimulating factor in transgenic tomato suspension cultures. Biotechnol. Lett. 2003, 25, 1571-1574.

[94] Kim, N.-S., Kim, T.-G., Kim, O.-H., Ko, E.-M. et al., Improvement of recombinant hGM-CSF production by suppression of cysteine proteinase gene expression using RNA interference in a transgenic rice culture. Plant Mol. Biol. 2008, 68, 263-275.

[95] Góra-Sochacka, A., Redkiewicz, P., Napiórkowska, B., Gaganidze, D. et al., Recombinant mouse granulocyte-macrophage colonystimulating factor is glycosylated in transgenic tobacco and maintains its biological activity. J. Interferon Cytokine Res. 2010, 30, 135-142.

[96] Ma, S., Huang, Y., Davis, A., Yin, Z. et al., Production of biologically active human interleukin-4 in transgenic tobacco and potato. Plant Biotechnol. J. 2005, 3, 309-318.

[97] Patel, J., Zhu, H., Menassa, R., Gyenis, L. et al., Elastin-like polypeptide fusions enhance the accumulation of recombinant proteins in tobacco leaves. Transgenic Res. 2007, 16, 239-249.

[98] Menassa, R., Kennette, W., Nguyen, V., Rymerson, R. et al., Subcellular targeting of human interleukin-10 in plants. J. Biotechnol. 2004, 108, 179-183.

[99] Farran, I., Río-Manterola, F., Íñiguez, M., Gárate, S., et al. Highdensity seedling expression system for the production of bioactive human cardiotrophin-1, a potential therapeutic cytokine, in transgenic tobacco chloroplasts. Plant Biotechnol. J. 2008, 6, 516-527.

[100] Potula, H. H. S., Kathuria, S., Ghosh, A. K., Maiti, T. K., Dey, S., Transient expression, purification and characterization of bioactive human fibroblast growth factor $8 \mathrm{~b}$ in tobacco plants. Transgenic Res. 2008, 17, 19-32.

[101] Lowther, W., Lorick, K., Lawrence, S., Yeow, W.-S., Expression of biologically active human interferon alpha 2 in Aloe vera. Transgenic Res. 2012, 21, 1349-1357.

[102] Morandini, F., Avesani, L., Bortesi, L., Van Droogenbroeck, B. et al., Non-food/feed seeds as biofactories for the high-yield production 
of recombinant pharmaceuticals. Plant Biotechnol. J. 2011, 9, 911-921.

[103] Ning, T., Xie, T., Qiu, Q., Yang, W. et al., Oral administration of recombinant human granulocyte-macrophage colony stimulating factor expressed in rice endosperm can increase leukocytes in mice. Biotechnol. Lett.. 2008, 30, 1679-1686.

[104] Ohya, K., Itchoda, N., Ohashi, K., Onuma, M. et al., Expression of biologically active human tumor necrosis factor-alpha in transgenic potato plant. J. Interferon Cytokine Res. 2002, 22, 371-378.

[105] Fukuzawa, N., Tabayashi, N., Okinaka, Y., Furusawa, R. et al., Production of biologically active Atlantic salmon interferon in transgenic potato and rice plants. J. Biosci. Bioeng. 2010, 110, 201-207.

[106] Zhou, F., Wang, M.-L., Albert, H., Moore, P., Zhu, Y., Efficient transient expression of human GM-CSF protein in Nicotiana benthamiana using potato virus X vector. Appl. Microbiol. Biotechnol. 2006, 72, 756-762.

[107] Musiychuk, K., Sivalenka, R., Jaje, J., Bi, H. et al., Plant-produced human recombinant erythropoietic growth factors support erythroid differentiation in vitro. Stem Cells Dev. 2013, 22, 2326-40.

[108] Song, L., Zhao, D., Wu, Y., Li, Y., Transient expression of chicken alpha interferon gene in lettuce. J. Zhejiang Univ. SCi B. 2008, 9, 351-355.

[109] Li, J., Chen, M., Liu, X.-W., Zhang, H.-C. et al., Transient expression of an active human interferon-beta in lettuce. Sci. Hortic. (Amsterdam). 2007, 112, 258-265.
[110] Nagels, B., Van Damme, E. J. M., Callewaert, N., Zabeau, L. et al., Biologically active, magnICON ${ }^{\circledR}$-expressed EPO-FC from stably transformed Nicotiana benthamiana plants presenting tetraantennary N-glycan structures. J. Biotechnol. 2012, 160, 242-250.

[111] Conley, A. J., Joensuu, J. J., Jevnikar, A. M., Menassa, R., Brandle, J. E., Optimization of elastin-like polypeptide fusions for expression and purification of recombinant proteins in plants. Biotechnol. Bioeng. 2009, 103, 562-573.

[112] Conley, A. J., Mohib, K., Jevnikar, A. M., Brandle, J. E., Plant recombinant erythropoietin attenuates inflammatory kidney cell injury. Plant Biotechnol. J. 2009, 7, 183-199.

[113] Eichler-Stahlberg, A., Weisheit, W., Ruecker, O., Heitzer, M., Strategies to facilitate transgene expression in Chlamydomonas reinhardtii. Planta. 2009, 229, 873-883.

[114] Sperb, F., Werlang, I. R., Margis-Pinheiro, M., Basso, L. et al., Molecular Cloning and Transgenic Expression of a Synthetic Human Erythropoietin Gene in Tobacco. Appl. Biochem. Biotechnol. 2011, 165, 652-665.

[115] Castilho, A., Neumann, L., Daskalova, S., Mason, H. S. et al., Engineering of Sialylated Mucin-type O-Glycosylation in Plants. J. Biol. Chem. 2012, 287, 36518-36526.

[116] Kittur, F., Hung, C.-Y., Darlington, D., Sane, D., Xie, J., N-Glycosylation engineering of tobacco plants to produce asialoerythropoietin. Plant Cell. Rep. 2012, 31, 1233-1243. 
Our latest Biotech Methods \& Advances special issue is edited by our Editors-in-Chief Prof. Alois Jungbauer and Prof. Sang Yup Lee. As always, the special issue is a collection of the latest breakthroughs in biotechnology. The cover is a graphical representation of some of the tools in biotechnology research. Image: (C) Bank-Bank - Fotolia.com.

\section{Biotechnology Journal - list of articles published in the January 2014 issue.}

Editorial: Latest methods and advances in biotechnology

Sang Yup Lee and Alois Jungbauer

http://dx.doi.org/10.1002/biot.201300522

Editorial: Biotechnology Journal - a review of 2013 and a preview of 2014

Judy Peng

http://dx.doi.org/10.1002/biot.201300524

Review

Physiologically relevant organs on chips

Kyungsuk Yum, Soon Gweon Hong, Kevin E. Healy and Luke P. Lee

http://dx.doi.org/10.1002/biot.201300187

Review

Large-scale production of red blood cells from stem cells:

What are the technical challenges ahead?

Guillaume F. Rousseau, Marie-Catherine Giarratana and

Luc Douay

http://dx.doi.org/10.1002/biot.201300368

Review

Molecular farming of human cytokines and blood products

from plants: Challenges in biosynthesis and detection

of plant-produced recombinant proteins

Nicolau B. da Cunha, Giovanni R. Vianna, Thaina da Almeida Lima and Elíbio Rech

http://dx.doi.org/10.1002/biot.201300062

Review

Biomaterial and cellular properties as examined through atomic force microscopy, fluorescence optical microscopies and spectroscopic techniques

Birgit Kainz, Ewa A. Oprzeska-Zingrebe and José L. Toca-Herrera http://dx.doi.org/10.1002/biot.201300087

Review

Microbial heterogeneity affects bioprocess robustness:

Dynamic single-cell analysis contributes to understanding

of microbial populations

Frank Delvigne and Philippe Goffin

http://dx.doi.org/10.1002/biot.201300119

Review

Algal biomass conversion to bioethanol - a step-by-step assessment Razif Harun, Jason W. S. Yip, Selvakumar Thiruvenkadam, Wan A. W. A. K. Ghani, Tamara Cherrington and Michael K. Danquah

http://dx.doi.org/10.1002/biot.201200353

Research Article

Recovery of Chinese hamster ovary host cell proteins for proteomic analysis

Kristin N. Valente, Amy K. Schaefer, Hannah R. Kempton,

Abraham M. Lenhoff and Kelvin H. Lee

http://dx.doi.org/10.1002/biot.201300190
Research Article

Highly sialylated recombinant human erythropoietin production in large-scale perfusion bioreactor utilizing CHO-gmt4 (JW152) with restored GnT I function

John S. Y. Goh, Yingwei Liu, Haifeng Liu, Kah Fai Chan, Corrine Wan, Gavin Teo, Xiangshan Zhou, Fusheng Xie, Peiqing Zhang, Yuanxing Zhang, Zhiwei Song

http://dx.doi.org/10.1002/biot.201300301

Research Article

Secretory ranalexin produced in recombinant Pichia pastoris exhibits additive or synergistic bactericidal activity when used in combination with polymyxin B or linezolid against multi-drug resistant bacteria Rasha Abou Aleinein, Holger Schäfer and Michael Wink http://dx.doi.org/10.1002/biot.201300282

Research Article

Engineering stress tolerance of Escherichia coli by stress-induced mutagenesis (SIM)-based adaptive evolution

Linjiang Zhu, Zhen Cai, Yanping Zhang and Yin Li

http://dx.doi.org/10.1002/biot.201300277

Research Article

Mini-scale cultivation method enables expeditious plasmid production in Escherichia coli

Petra Grunzel, Maciej Pilarek, Dörte Steinbrück, Antje Neubauer, Eva Brand, Michael U. Kumke, Peter Neubauer and Mirja Krause http://dx.doi.org/10.1002/biot.201300177

Research Article

A magnetic nanobead-based bioassay provides sensitive detection of single- and biplex bacterial DNA using a portable AC susceptometer Mattias Strömberg, Teresa Zardán Gómez de la Torre, Mats Nilsson, Peter Svedlindh and Maria Strømme

http://dx.doi.org/10.1002/biot.201300348

Research Article

Hydrostatic pressure and shear stress affect endothelin-1 and nitric oxide release by endothelial cells in bioreactors

Federico Vozzi, Francesca Bianchi, Arti Ahluwalia and

Claudio Domenici

http://dx.doi.org/10.1002/biot.201300016

Technical report

A protease substrate profiling method that links site-specific proteolysis with antibiotic resistance

Lisa Sandersjöö, George Kostallas, John Löfblom and

Patrik Samuelson

http://dx.doi.org/10.1002/biot.201300234

Rapid Communication

Albumin-based nanocomposite spheres for advanced drug delivery systems

Heath E. Misak, Ramazan Asmatulu, Janani S. Gopu, Ka-Poh Man, Nora M. Zacharias, Paul H. Wooley and Shang-You Yang http://dx.doi.org/10.1002/biot.201300150 